\title{
Cardiovascular variability in Mexican patients with Parkinson's disease
}

\author{
Variabilidade cardiovascular em pacientes mexicanos com doença de Parkinson \\ Guillermo Delgado", Bruno Estañol', Mayela Rodríguez-Violante², Raúl Martínez-Memije ${ }^{3}$, \\ Óscar Infante-Vázquez ${ }^{3}$, Nancy Bertado-Ramírez ${ }^{1}$
}

\begin{abstract}
Cardiovascular variability (CVV) has been evaluated in patients with Parkinson's disease (PD) in other countries and exhibit ethnic differences. Objective: We investigated heart rate variability (HRV) and blood pressure variability (BPV) in Mexican patients with PD. Method: We further compared HRV and BPV between this group and young healthy controls (YHC) in order to estimate, for the first time in our country, the magnitude of the difference. Twenty patients were examined. Time- and frequency-domain CVV parameters were studied during supine rest (SR), active standing (AS) and controlled breathing. These measurements were compared to those of $20 \mathrm{YHC}$. Results: In the three conditions tested, our study showed a decrease in almost all HRV parameters in PD patients; on the contrary, decreased BPV parameters were found less frequently and only during SR and AS. Conclusion: Our results indicate that HRV is impaired in PD. Some BPV parameters are also diminished.
\end{abstract}

Keywords: Parkinson's disease, autonomic nervous system, heart rate variability, blood pressure variability, dysautonomia.

\section{RESUMO}

A variabilidade cardiovascular (VCV) tem sido avaliada em doentes parkinsonianos em vários países e apresenta diferenças étnicas. Objetivo: Investigar a variabilidade da frequência cardíaca (VFC) e a variabilidade da pressão arterial (VPA) em doentes parkinsonianos mexicanos. Método: Comparamos VFC e VPA entre o grupo de estudo e controles jovens (CJ), a fim de estimar a magnitude da diferença. CV foi estudada no domínio do tempo e da frequência durante repouso supino (RS), ortostase ativa (OA) e respiração controlada. Estas medições foram comparadas com aquelas de 20 CJ. Resultados: Nosso estudo mostrou diminuição em quase todos os parâmetros da VFC em doentes parkinsonianos. A diminuição dos parâmetros da VPA foi encontrada com menos frequência. Conclusão: Nossos resultados indicam que a VFC é prejudicada na doença de Parkinson. Alguns parâmetros do VPA também são reduzidos.

Palavras-chave: doença de Parkinson, sistema nervoso autônomo, variabilidade da frequência cardíaca, variabilidade da pressão arterial, disreflexia autonômica.

The clinical features of Parkinson's disease (PD) are not restricted to the classical triad of resting tremor, rigidity, and bradykinesia, but also include autonomic disturbances ${ }^{1}$, which were first noted by James Parkinson in his original description. Concretely, the prevalence of clinically relevant dysautonomia in PD exceeds $50 \%^{2}$. The period between the onset of neurodegeneration and appearance of the cardinal motor signs is referred to as premotor or prodromal phase of PD and its duration has been estimated to be from years to decades ${ }^{3}$. During this phase patients later diagnosed with PD have more autonomic symptoms than control subjects $^{3,4}$. Likewise, existing reports indicate that autonomic dysfunction occurs before any medical intervention and often precedes motor disturbances ${ }^{5}$.

All three branches of the autonomic nerve system (ANS) are affected in $\mathrm{PD}^{6}$. Sympathetic cardioneuropathy was first described about 15 years ago using 6-[18F]fluorodopamine positron-emission tomography and later confirmed by neuropathological and neuroimaging findings ${ }^{7}$. Furthermore, Shibata et al. demonstrated that in the early stages of PD, cardiovagal dysfunction occurs concurrently with cardiosympathetic denervation ${ }^{6}$, but possibly the latter is incom-

\footnotetext{
${ }^{1}$ Laboratory of Clinical Neurophysiology, Department of Neurology and Psychiatry, National Institute of Medical Sciences and Nutrition Salvador Zubirán (INNSZ), Monterrey, Nuevo León, Mexico;

${ }^{2}$ Movement Disorders Clinic, National Institute of Neurology and Neurosurgery Manuel Velasco Suárez (INNN), Mexico DF, Mexico;

${ }^{3}$ Department of Electromechanical Instrumentation, National Institute of Cardiology Ignacio Chávez (INC), Mexico DF, Mexico.

Correspondence: Guillermo Delgado; Laboratory of Clinical Neurophysiology, National Institute of Medical Sciences and Nutrition Salvador Zubirán (INNSZ); Vasco de Quiroga 15, Tlalpan; CP 14000, México DF, México; E-mail: grdelgadog@gmail.com

Conflict of interest: There is no conflict of interest to declare.

Received 28 February 2014; Received in final form 25 June 2014; Accepted 15 July 2014.
} 
plete and the remaining fibers are sufficient for the maintenance of sympathetic control ${ }^{8}$. Neuropathological studies have demonstrated the presence of Lewy bodies (LB) in both tyrosine hydroxylase-positive and -negative nerve processes of the cardiac plexus, and also in Auerbach's and Meissner's plexuses ${ }^{5,6}$. The occurrence of prodromal symptoms appears to correspond to the neuropathological staging of PD-associated LB pathology as proposed by Braak et al. and later modified by Przuntek et al. ${ }^{3}$. The cardiovascular autonomic assessment is therefore of chief importance in PD. As previous studies have shown ethnic differences in cardiovascular variability $(\mathrm{CVV})^{9}$; the purpose of the current study was to investigate it, for the first time, in Mexican patients with PD.

\section{METHOD}

Heart rate variability (HRV) analysis is a widely accepted, non-invasive, method for indirect assessment of the ANS activity $^{10}$. This method, which provides information on sympathetic and parasympathetic modulation of the sinus node, has been utilized in many studies involving PD. Despite an obvious lack of parasympathetic innervation to the systemic vasculature (which presumably allows an exclusive evaluation of the sympathetic system), blood pressure variability (BPV) analysis has received far less attention than $\mathrm{HRV}^{5}$. Short-term CVV can be calculated by means of both timeand frequency-domain techniques ${ }^{11,12}$. Certain HRV parameters have been shown to act as independent predictors of mortality in postinfarcted ${ }^{11}$, chronically hemodialyzed ${ }^{13}$, heart failure ${ }^{14}$, diabetic ${ }^{15}$ and hemodynamically stable trauma patients ${ }^{16}$. A decrease in BPV has been reported in patients with mildly impaired renal function ${ }^{17}$, renovascular hypertension $^{18}$ and congestive heart failure ${ }^{19}$. However, the effect of this reduction on patient mortality is unknown.

\section{Study population}

We studied autonomic function in 20 patients with mildto-moderate PD (13 males, mean age 60.9 \pm 6.27 years, mean duration of disease $3.65 \pm 2.39$ years, Hoehn and Yahr stage $\leq 3$ ). All participants with PD fulfilled the UK Brain Bank Clinical Criteria. None of these patients had evidence of diabetes mellitus or hypertension. PD group was not divided into subgroups according to their treatment, since previous studies have found little or no difference as to whether the patient was or was not taking medication ${ }^{5,20}$. As control group, we included 20 young subjects (9 males, mean age $37.6 \pm 8.84$ years) who were in good health status as determined by physical exam. This study was approved by the Ethical Committee of the National Institute of Medical Sciences and Nutrition and an informed written consent was obtained from all patients and controls.

\section{Protocol}

Evaluations were performed between 9:00 and 11:00. Participants in both groups were instructed to avoid alcohol, caffeinated beverages and over-the-counter medications after 22:00 on the night before the measurements. A photoplethysmographic finger cuff was wrapped on the midphalanx of the left index finger and placed in the midaxillary line at heart level for continuous non-invasive beat-to-beat recording of blood pressure (BP) and interbeat intervals (IBI) using the volume-clamp technique of Peńa (Finometer ${ }^{\circledR}$ PRO, Finapres Medical Systems, Amsterdam). Relatively short recordings ( $\approx 6$ minutes) were obtained in each of the following conditions: supine rest (SR), active standing (AS) and $0.1 \mathrm{~Hz}$ controlled breathing (CB). The latter frequency was chosen because it profoundly increases HRV power to an individual maximum in normal subjects ${ }^{21}$. Total recording time per subject was approximately 40 minutes. All participants completed the three conditions. Hemodynamic parameters were extracted with BeatScope ${ }^{\circledR}$ (Finapres Medical Systems).

\section{Data analysis and statistics}

All data were entered into Microsoft Excel ${ }^{\circledR}$ spreadsheets. Prior to all analyses, hemodynamic parameters were visually inspected and artifacts were manually removed and corrected by means of linear interpolation. Only stable recordings were included for analysis. Kubios HRV $^{\circledR}$ (v.2.0, Biosignal Analysis and Medical Imaging Group, University of Eastern Finland) was used to generate the following parameters from the recorded $\mathrm{IBI}^{11}$ : mean and standard deviation of heart rate (MHR, SDHR, bpm), standard deviation of all IBI (standard deviation of all normal-to-normal intervals, SDNN, ms), square root of the mean of the sum of the squares of differences between adjacent IBI (square root of the mean of the sum of the squares of differences between adjacent NNI, RMSSD, ms), number of pairs of adjacent IBI differing by more than $50 \mathrm{~ms}$ in the entire recording (NN50), percentage of adjacent IBI differing by more than $50 \mathrm{~ms}$ in the entire recording ( $\mathrm{pNN} 50)$, total power $\left(\mathrm{TP}, \mathrm{ms}^{2}\right)$, power in low frequency range (LF, 0.04-0.15 Hz, ms ${ }^{2}$ ), power in high frequency range $\left(\mathrm{HF}, 0.15-0.4 \mathrm{~Hz}, \mathrm{~ms}^{2}\right), \mathrm{LF}$ in normalized units $\left(\mathrm{LF}_{\mathrm{nu}}\right)$, HF in normalized units $\left(\mathrm{HF}_{\mathrm{nu}}\right)$ and the ratio between LF/HF (LF/HF). Spectral analysis was performed by Kubios $\mathrm{HRV}^{\circledR}$ through a Fast Fourier Transformation (FFT) of the IBI time series. In addition, a software written in MATLAB $^{\circledR}$ (v.R2012a, MathWorks, Massachusetts) was developed to spectrally analyze the BP by applying FFT. These parameters were generated by the software: TP $\left(\mathrm{mmHg}^{2}\right)$, LF $\left(\mathrm{mmHg}^{2}\right)$ and $\mathrm{HF}\left(\mathrm{mmHg}^{2}\right)$. Time domain parameters of BPV were calculated with STATISTICA for Windows ${ }^{\circledR}$ (v.5.1). Statistical analysis was performed with the same software. Prior to group analyses, individual data were tested for normality (Shapiro-Wilk test). Comparison 
between the two groups was performed by either using Student's t-test or Mann-Whitney U test. A p-value below $0.05(\mathrm{p}<0.05)$ was considered significant. All results are expressed as mean \pm SD or median (range).

\section{RESULTS}

\section{HRV}

All the parameters studied for both groups were significantly different during SR, except for maximal heart rate $\left(\mathrm{HR}_{\max }\right)$. The following time-domain parameters were higher in PD as compared to young healthy controls (YHC): MHR and minimal heart rate $\left(\mathrm{HR}_{\min }\right)$. On the contrary, the remaining time-domain parameters were comparatively lower (SDHR, SDNN, RMSSD, NN50 and pNN50). With respect to the frequency domain, TP $\left(\mathrm{ms}^{2}\right), \mathrm{LF}\left(\mathrm{ms}^{2}\right)$, HF $\left(\mathrm{ms}^{2}\right)$ and $\mathrm{HF}_{\mathrm{nu}}$ were also comparatively lower in $\mathrm{PD}$; whereas the opposite occurred with $\mathrm{LF}_{\mathrm{nu}}$ and $\mathrm{LF} / \mathrm{HF}$. These results are shown in Table 1 . MHR, $\mathrm{HR}_{\max }, \mathrm{HR}_{\min }$, $\mathrm{LF}_{\mathrm{nu}}, \mathrm{HF}_{\mathrm{nu}}$ and $\mathrm{LF} / \mathrm{HF}$ were not significantly different between the two groups during AS; while all other parameters were lower in PD as compared to YHC. These results are shown in Table 2. $\mathrm{HR}_{\max }, \mathrm{LF}_{\mathrm{nu}}, \mathrm{HF}_{\mathrm{nu}}$ and $\mathrm{LF} / \mathrm{HF}$ were not significantly different between the two groups during CB; whilst SDHR, SDNN, RMSSD, NN50, pNN50, TP $\left(\mathrm{ms}^{2}\right)$, $\mathrm{LF}\left(\mathrm{ms}^{2}\right)$ and $\mathrm{HF}\left(\mathrm{ms}^{2}\right)$ were comparatively lower in PD. The remaining time-domain parameters were contrarily higher (MHR and $\mathrm{HR}_{\text {min }}$ ). These results are shown in Table 3.

Table 1. Heart rate variability (HRV) in supine rest (SR).

\begin{tabular}{|c|c|c|}
\hline & $P D(n=20)$ & YHC $(n=20)$ \\
\hline MHR (bpm) & $72.8 \pm 11.77 \star$ & $66.32 \pm 7.6$ \\
\hline SDHR (bpm) & $2.03 \pm 0.73^{*}$ & $3.24 \pm 1.37$ \\
\hline $\mathrm{HR}_{\max }(\mathrm{bpm})$ & $80 \pm 12.08$ & $78.6 \pm 9.23$ \\
\hline $\mathrm{HR}_{\min }(\mathrm{bpm})$ & $67.45 \pm 11.56^{*}$ & $58.1 \pm 8.84$ \\
\hline SDNN (ms) & $23.38(16.74-27.68)^{*}$ & $38.75(27.25-49.47)$ \\
\hline RMSSD (ms) & $15.31(13.03-24.29)^{\star}$ & $34.29(25-54.25)$ \\
\hline NN50 & $1(0-11)^{\star}$ & $43.5(8-103.5)$ \\
\hline pNN50 (\%) & $0.30(0-2.95)^{*}$ & $13.06(3.06-36.03)$ \\
\hline $\mathrm{TP}\left(\mathrm{ms}^{2}\right)$ & $381.5(222-607)^{\star}$ & $1170.5(647-2297)$ \\
\hline $\mathrm{LF}\left(\mathrm{ms}^{2}\right)$ & $114.94(66.89-152.77) *$ & $298.47(211.30-751.72)$ \\
\hline $\mathrm{HF}\left(\mathrm{ms}^{2}\right)$ & $60.87(33.86-100.05)^{\star}$ & 271.96 (216.61-865.29) \\
\hline$L F_{n u}$ & $63.73 \pm 16.98 *$ & $51.78 \pm 19.27$ \\
\hline $\mathrm{HF}_{\mathrm{nu}}$ & $36.27 \pm 16.98^{*}$ & $48.22 \pm 19.27$ \\
\hline LF/HF & $1.96(1.16-3.63)^{\star}$ & $1.08(0.52-1.91)$ \\
\hline
\end{tabular}

All results are expressed as mean \pm SD or median (range). PD: Parkinson disease; YHC: Young healthy controls; bpm: Beats per minute; MHR: Mean heart rate; SDHR: Standard deviation of heart rate; HR max: Maximal heart rate; $\mathrm{HR}_{\min }$ : Minimal heart rate; SDNN: Standard deviation of all normalto-normal intervals (NNI); RMSSD: Square root of the mean of the sum of the squares of differences between adjacent NNI; NN50: Number of pairs of adjacent NNI differing by more than $50 \mathrm{~ms}$ in the entire recording; pNN50: NN50 count divided by the total number of all NNI; TP: Total power: LF: Power in low frequency range $(0.04-0.15 \mathrm{~Hz})$; HF: Power in high frequency range $(0.15-0.4 \mathrm{~Hz})$; $L F_{n u}$ : LF in normalized units; $H F_{n u}$ : $H F$ in normalized units; LF/HF: Ratio between LF/HF. ${ }^{\star} p<0.05$ PD vs. YHC.
Table 2. Heart rate variability (HRV) in active standing (AS).

\begin{tabular}{|c|c|c|}
\hline & $P D(n=20)$ & YHC $(n=20)$ \\
\hline MHR (bpm) & $80.65 \pm 11.81$ & $79.67 \pm 10.9$ \\
\hline SDHR (bpm) & $2.14 \pm 0.63^{\star}$ & $4.72 \pm 1.8$ \\
\hline$H R_{\max }(b p m)$ & $87.65 \pm 11.71$ & $92.4 \pm 11.86$ \\
\hline $\mathrm{HR}_{\min }(\mathrm{bpm})$ & $69.5(65-84)$ & $69(59-74.5)$ \\
\hline SDNN (ms) & $23.49(18.68-30.23)^{\star}$ & $43.66(28.74-58.4)$ \\
\hline RMSSD (ms) & $15.7(11.02-20.97)^{\star}$ & 26.9 (21.79-34.38) \\
\hline NN50 & $0.5(0-4)^{\star}$ & $21(6.5-45)$ \\
\hline pNN50 (\%) & $0.14(0-1.35)^{\star}$ & $5.94(2.15-15.41)$ \\
\hline $\mathrm{TP}\left(\mathrm{ms}^{2}\right)$ & $403.5(287.5-724) \star$ & $1624.5(851-3503)$ \\
\hline $\mathrm{LF}\left(m \mathrm{~s}^{2}\right)$ & $99.91(44.49-156.95) *$ & 510.1 (248.22-1497.23) \\
\hline $\mathrm{HF}\left(\mathrm{ms}^{2}\right)$ & $60.97(29.79-111.84)^{*}$ & $320.68(251.45-791.4)$ \\
\hline$L F_{n u}$ & $58.79 \pm 18.99$ & $58.52 \pm 22.61$ \\
\hline $\mathrm{HF}_{\mathrm{nu}}$ & $41.21 \pm 18.986$ & $41.48 \pm 22.61$ \\
\hline LF/HF & $1.46(0.76-3.24)$ & $1.36(0.81-3.27)$ \\
\hline
\end{tabular}

All results are expressed as mean \pm SD or median (range). PD: Parkinson disease; YHC: Young healthy controls; bpm: Beats per minute; MHR: Mean heart rate; SDHR: Standard deviation of heart rate; $\mathrm{HR}_{\max }$ : Maximal heart rate; $\mathrm{HR}_{\min }$ : Minimal heart rate; SDNN: Standard deviation of all normalto-normal intervals (NNI); RMSSD: Square root of the mean of the sum of the squares of differences between adjacent NNI; NN50: Number of pairs of adjacent $\mathrm{NNI}$ differing by more than $50 \mathrm{~ms}$ in the entire recording; pNN50: NN50 count divided by the total number of all NNI; TP: Total power; LF: Power in low frequency range $(0.04-0.15 \mathrm{~Hz})$; HF: Power in high frequency range $(0.15-0.4 \mathrm{~Hz})$; $L F_{n u}$ : $L F$ in normalized units; $\mathrm{HF}_{\mathrm{nu}}$ : $\mathrm{HF}$ in normalized units; LF/HF: Ratio between LF/HF. ${ }^{\star} p<0.05$ PD vs. YHC.

Table 3. Heart rate variability (HRV) in controlled breathing (CB).

\begin{tabular}{|c|c|c|}
\hline & $P D(n=20)$ & $\mathrm{YHC}(n=20)$ \\
\hline MHR (bpm) & $69.85(66.72-86.12)^{\star}$ & 66.24 (62.54-73.71) \\
\hline SDHR (bpm) & $3.12(2.81-3.85)^{\star}$ & $6.15(4.49-7.47)$ \\
\hline$H R_{\max }(b p m)$ & $80(74.5-95)$ & $86(77-91)$ \\
\hline$H R_{\min }(b p m)$ & $67.9 \pm 14.23 *$ & $55.7 \pm 8.33$ \\
\hline SDNN (ms) & $35.14(23.6-48.9)^{\star}$ & $79.57(64.49-105.4)$ \\
\hline RMSSD (ms) & $19.65(15.29-24.55)^{*}$ & $47.08(36.16-76.42)$ \\
\hline NN50 & $3.5(0-15)^{\star}$ & $90.5(53.5-132)$ \\
\hline pNN50 (\%) & $0.93(0-4.8)^{\star}$ & $25(15.42-44.55)$ \\
\hline $\mathrm{TP}\left(\mathrm{ms}^{2}\right)$ & $1127.5(411.5-1632)^{\star}$ & $6265(3137-10158)$ \\
\hline $\mathrm{LF}\left(m \mathrm{~s}^{2}\right)$ & $799.97(258.39-1215.24)^{*}$ & 4769.38 (2231.5-7845.16) \\
\hline $\mathrm{HF}\left(\mathrm{ms}^{2}\right)$ & $66.84(25.66-179.69)^{\star}$ & $530.29(294.09-1185.47)$ \\
\hline $\mathrm{LF}_{\mathrm{nu}}$ & $89.72(80.33-94.04)$ & $88.74(82.27-91.26)$ \\
\hline $\mathrm{HF}_{\mathrm{nu}}$ & $10.28(5.96-19.67)$ & $11.26(8.74-17.73)$ \\
\hline LF/HF & $8.74(4.17-15.93)$ & $7.9(4.69-10.44)$ \\
\hline
\end{tabular}

All results are expressed as mean \pm SD or median (range). PD: Parkinson disease; YHC: Young healthy controls; bpm: Beats per minute; MHR: Mean heart rate; SDHR: Standard deviation of heart rate; $\mathrm{HR}_{\max }$ : Maximal heart rate; $\mathrm{HR}_{\text {min }}$ : Minimal heart rate; SDNN: Standard deviation of all normalto-normal intervals (NNI); RMSSD: Square root of the mean of the sum of the squares of differences between adjacent NNI; NN50: Number of pairs of adjacent NNI differing by more than $50 \mathrm{~ms}$ in the entire recording; pNN50: NN50 count divided by the total number of all NNI; TP: Total power; LF: Power in low frequency range $(0.04-0.15 \mathrm{~Hz})$; HF: Power in high frequency range $(0.15-0.4 \mathrm{~Hz})$; $L F_{n u}$ : $L F$ in normalized units; $H F_{n u}$ : $H F$ in normalized units; LF/HF: Ratio between LF/HF. ${ }^{\star} p<0.05$ PD vs. YHC.

\section{BPV}

Mean systolic blood pressure (MSBP), maximal systolic blood pressure $\left(\mathrm{SBP}_{\max }\right)$ and minimal systolic blood pressure $\left(\mathrm{SBP}_{\min }\right)$ were lower in $\mathrm{PD}$ as compared to $\mathrm{YHC}$ during $\mathrm{SR}$. With respect to the frequency domain, TP $\left(\mathrm{mmHg}^{2}\right)$ were also comparatively lower in PD. All other parameters were 
Table 4. Blood pressure variability (BPV) in supine rest (SR).

\begin{tabular}{lcc}
\hline & $P D(n=20)$ & YHC $(n=20)$ \\
\hline MSBP $(m m H g)$ & $96.7 \pm 11.01^{\star}$ & $110.04 \pm 10.3$ \\
SDSBP $(m m H g)$ & $3.55(3.17-4.47)$ & $5.01(3.31-5.69)$ \\
$\mathrm{SBP}_{\max }(\mathrm{mmHg})$ & $107.45 \pm 14.15^{\star}$ & $125.1 \pm 12.12$ \\
$\mathrm{SBP}_{\min }(\mathrm{mmHg})$ & $86.1 \pm 9.44^{\star}$ & $99.8 \pm 10.87$ \\
& 2663.36 & 5706.4 \\
$\mathrm{TP}\left(\mathrm{mmHg} \mathrm{g}^{2}\right)$ & $(2074.87-3489.05)^{\star}$ & $(2538.67-9106.83)$ \\
$\mathrm{LF}\left(\mathrm{mmH} \mathrm{g}^{2}\right)$ & $949.2(816.29-1336.2)$ & $2049.8(880.7-4033.3)$ \\
$\left.\mathrm{HF}(\mathrm{mmHg})^{2}\right)$ & $196.77(72.49-391.79)$ & $274.13(169.74-433.85)$ \\
\hline
\end{tabular}

All results are expressed as mean \pm SD or median (range). PD: Parkinson disease; YHC: Young healthy controls; mmHg: Millimeter of mercury; MSBP: Mean systolic blood pressure; SDSBP: Standard deviation of systolic blood pressure; $\mathrm{SBP}_{\max }$ : Maximal systolic blood pressure; $\mathrm{SBP}_{\min }$ : Minimal systolic blood pressure; TP: Total power; LF: Power in low frequency range $(0.04-0.15 \mathrm{~Hz})$; HF: Power in high frequency range $(0.15-$ $0.4 \mathrm{~Hz}) .{ }^{\star} \mathrm{p}<0.05 \mathrm{PD}$ vs. YHC.

Table 5. Blood pressure variability (BPV) in active standing (AS).

\begin{tabular}{lcc}
\hline & PD $(n=20)$ & YHC $(n=20)$ \\
\hline MSBP $(\mathrm{mmHg})$ & $110.04(96.7-119.17)$ & $112.3(105-116.67)$ \\
SDSBP $(\mathrm{mmHg})$ & $5.77 \pm 1.93$ & $5.38 \pm 1.36$ \\
$\mathrm{SBP}_{\max }(\mathrm{mmHg})$ & $120.1 \pm 20.36$ & $126.3 \pm 13.19$ \\
$\mathrm{SBP}_{\min }(\mathrm{mmHg})$ & $97(81.5-105.5)$ & $98.5(89.5-104)$ \\
& 4605.36 & 6889.59 \\
$\mathrm{TP}\left(\mathrm{mmHg}^{2}\right)$ & $(3818.56-6788.5)$ & $(4502.44-9850.48)$ \\
& 1766.15 & 3210.53 \\
$\mathrm{LF}\left(\mathrm{mmHg}^{2}\right)$ & $(1466.25-2571.1) *$ & $(2323.25-4629.35)$ \\
$\left.\mathrm{HF}(\mathrm{mmHg})^{2}\right)$ & $277.53(170.15-560.71) *$ & $581.3(328.28-868.78)$ \\
\hline
\end{tabular}

All results are expressed as mean \pm SD or median (range). PD: Parkinson disease; YHC: Young healthy controls; $\mathrm{mmHg}$ : Millimeter of mercury; MSBP: Mean systolic blood pressure; SDSBP: Standard deviation of systolic blood pressure; SBP max: Maximal systolic blood pressure; SBP $\min$ : Minimal systolic blood pressure; TP: Total power; LF: Power in low frequency range $(0.04-0.15 \mathrm{~Hz})$; HF: Power in high frequency range (0.15-0.4 Hz). ${ }^{\star} \mathrm{p}<0.05 \mathrm{PD}$ vs. YHC.

not significantly different between groups. These results are shown in Table 4. Although most parameters were not significantly different between the two groups during AS, LF $\left(\mathrm{mmHg}^{2}\right)$ y HF $\left(\mathrm{mmHg}^{2}\right)$ were lower in PD as compared to YHC. These results are shown in Table 5. None of the parameters were significantly different between the groups during CB. These results are shown in Table 6.

\section{DISCUSSION}

\section{HRV}

Consistent with other studies ${ }^{1,10}$, our results showed a decrease in overall HRV (i. e., SDNN, TP) in PD as compared to YHC during the three conditions. More specifically, cardiovagal indicators (i. e., RMSSD, NN50, pNN50 and HF) $)^{1,10,11}$ were significantly reduced in PD. At rest LF variations are greatly mediated by vagal fluctuations ${ }^{10}$. Hence, we should be cautious when interpreting LF/HF elevation in PD during SR as sympathetic dominance. Conversely, if we consider the
Table 6. Blood pressure variability (BPV) in controlled breathing (CB).

\begin{tabular}{lcc} 
& PD $(n=20)$ & YHC $(n=20)$ \\
\hline MSBP $(\mathrm{mmHg})$ & $109.82 \pm 16.82$ & $114.75 \pm 13.76$ \\
$\operatorname{SDSBP}(\mathrm{mmHg})$ & $6.73 \pm 1.7$ & $6.77 \pm 1.55$ \\
$\mathrm{SBP}_{\max }(\mathrm{mmHg})$ & $126.05 \pm 16.87$ & $132.55 \pm 14.76$ \\
$\mathrm{SBP}_{\min }(\mathrm{mmHg})$ & $93.65 \pm 18.25$ & $98.2 \pm 14.33$ \\
& 7690.73 & 9868.15 \\
$\mathrm{TP}(\mathrm{mmHg})$ & $(6454.66-11269.14)$ & $(7817.11-13621.3)$ \\
$\mathrm{LF}\left(\mathrm{mmHg}^{2}\right)$ & 4796.96 & 6721.5 \\
$\mathrm{HF}\left(\mathrm{mmHg}^{2}\right)$ & $(3440.7-8116.7)$ & $(4231.65-9069.6)$ \\
\hline
\end{tabular}

All results are expressed as mean \pm SD or median (range). PD: Parkinson disease; YHC: Young healthy controls; mmHg: Millimeter of mercury; MSBP: Mean systolic blood pressure; SDSBP: Standard deviation of systolic blood pressure; SBP max: Maximal systolic blood pressure; $\mathrm{SBP}_{\min }$ : Minimal systolic blood pressure; TP: Total power; LF: Power in low frequency range (0.04-0.15 Hz); HF: Power in high frequency range $(0.15-0.4 \mathrm{~Hz})$.

traditional paradigms of spectral analysis of HRV during $\mathrm{AS}^{5,11}$, LF reduction reflects cardiosympathetic impairment in PD. $L_{\text {nu }}$ and $\mathrm{HF}_{\text {nu }}$ were not significantly different between groups during both AS and CB, this lack of difference indicates a proportional reduction of both $\operatorname{LF}\left(\mathrm{ms}^{2}\right)$ y HF $\left(\mathrm{ms}^{2}\right)$. In both groups, LF $\left(\mathrm{ms}^{2}\right)$ values were considerably increased in magnitude but different from each other during $\mathrm{CB}$, a condition known to augment cardiovagal control ${ }^{21}$. Nevertheless this finding does not reflect sympathetic dominance but rather an effect of low respiratory frequency $(<0.2 \mathrm{~Hz})$, which causes an overlap of the LF and HF components of CVV signals ${ }^{22,26}$.

\section{BPV}

Our results showed a decrease in overall BPV (i. e., TP) in PD as compared to YHC during SR. Despite this significant difference in TP $\left(\mathrm{mmHg}^{2}\right)$, LF $\left(\mathrm{mmHg}^{2}\right)$ and $\mathrm{HF}\left(\mathrm{mmHg}^{2}\right)$ were similar in both groups. One likely explanation for this apparently contradictory result is that power in very low frequency range $\left(\leq 0.04 \mathrm{~Hz}, \mathrm{mmHg}^{2}\right)$, whose nature remains unclear $^{24}$, is also part of TP. During AS, the opposite occurred: TP $\left(\mathrm{mmHg}^{2}\right)$ was similar in both groups and, notwithstanding this result, $\mathrm{LF}\left(\mathrm{mmHg}^{2}\right)$ and $\mathrm{HF}\left(\mathrm{mmHg}^{2}\right)$ were significantly different between the two groups. The above explanation is also quite plausible here. $\mathrm{LF}\left(\mathrm{mmHg}^{2}\right)$ was comparatively lower in PD during AS, this reduction in the so-called Mayer waves reflects an impairment in the vasosympathetic outflow ${ }^{5,25}$. Meanwhile, during SR, a similar though statistically not significant trend was noticed as shown in Figure. Vasosympathetic dysfunction in PD has been already reported ${ }^{25,26}$. The coincidence of $\mathrm{LF}\left(\mathrm{mmHg}^{2}\right)$ comparatively decreased in PD and MSBP similar between groups after orthostatic challenge (i. e., AS) is consistent with a previously proposed hypothesis that initial alterations of vasosympathetic control may primarily affect BPV and only subsequently induce changes in MSBP values leading to orthostatic hypotension ${ }^{25}$. As noted above, HF $\left(\mathrm{mmHg}^{2}\right)$ 


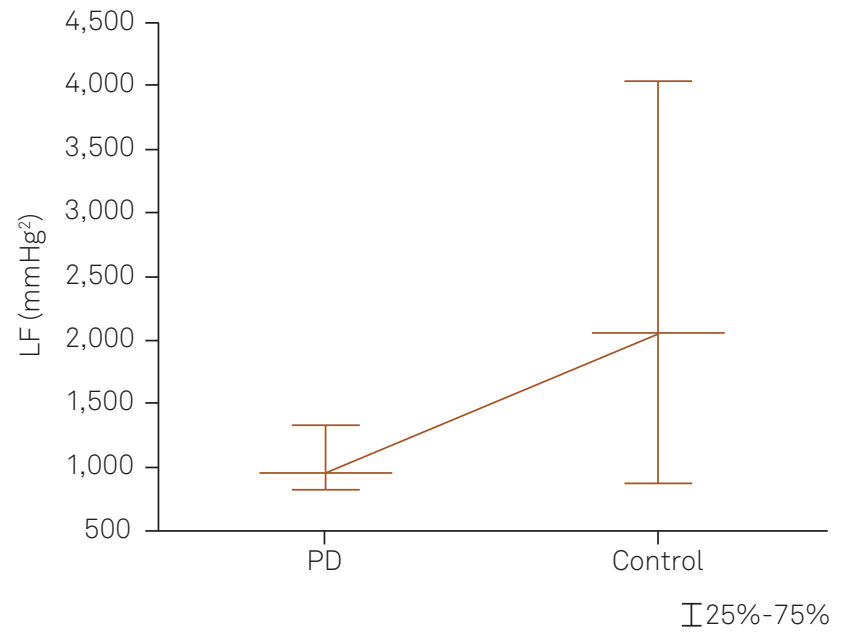

Figure. Low frequency (LF) $\left(\mathrm{mmHg}^{2}\right)$ was comparatively lower in Parkinson's disease (PD) during supine rest (SR) (though statistically not significant).

was lower in PD as compared to YHC. For an accurate interpretation of this result, it must be taken into account that this respiratory oscillation depends on fluctuation in cardiac output ${ }^{12,24,27}$. Finally, it is known that slow breathing $(0.1 \mathrm{~Hz})$ improves baroreflex sensitivity by increasing HRV and $\mathrm{BPV}^{28}$; this may partially explain the lack of a significant difference between the groups during CB. In both groups, $\mathrm{LF}\left(\mathrm{mmHg}^{2}\right)$ values were considerably increased in magnitude during $\mathrm{CB}$. This finding, as in the case of HRV, does not reflect sympathetic dominance but rather an effect of low respiratory frequency ${ }^{23}$.

To our knowledge, these findings are the first to document a blunted CVV in Mexican patients with PD $^{29}$. Such assessment is particularly relevant because CVV exhibit ethnic differences'. The mortality of PD patients is almost doubled compared with age- and sex-matched healthy controls, and it is worth noting that increased cardiovascular mortality has been also reported in parkinsonian patients (as for diabetic or postinfarcted patients). Therefore, the clinical implications of our results are consistent with a previously proposed hypothesis that cardiovascular autonomic dysfunction (which can be quantified by HRV analysis) can be at least partially responsible for the increased mortality in PD patients ${ }^{20}$. Lastly, the absence of a second control group of age-matched healthy subjects was the main limitation of this study, primarily since HRV decreases with age. Yet it has been reported that aging process has no influence on systolic $\mathrm{BPV}^{30}$.

\section{References}

1. Kallio M, Haapaniemi T, Turkka J, Suominem K, Tolonen U, Sotaniemi $K$ et al. Heart rate variability in patients with untreated Parkinson's disease. Eur J Neurol. 2000;7(6):667-72. http://dx.doi.org/10.1046/ j.1468-1331.2000.00127.x

2. Wolters ECh, Braak H. Parkinson's disease: premotor clinicopathological correlations. J Neural Transm Suppl. 2006;70:309-19. http://dx.doi.org/10.1007/978-3-211-45295-0_47

3. Gaenslen A, Swid I, Liepelt-Scarfone I, Godau J, Berg D et al. The patients' perception of prodromal symptoms before the initial diagnosis of Parkinson's disease. Mov Disord. 2011;26(4):653-8. http://dx.doi.org/10.1002/mds.23499

4. Gonera EG, Van't Hof M, Berger HJ, Weel C, Horstink MWIM. Symptoms and duration of the prodromal phase in Parkinson's disease. Mov Disord. 1997;12(6):871-6. http://dx.doi.org/10.1002/ mds.870120607

5. Brown R, Duma S, Piguet O, Broe GA, Macefield VG. Cardiovascular variability in Parkinson's disease and extrapyramidal motor slowing. Clin Auton Res. 2012;22(4):191-6. http://dx.doi.org/10.1007/s10286012-0163-9

6. Shibata M, Morita Y, Shimizu T, Takahashi K, Suzuki N. Cardiac parasympathetic dysfunction concurrent with cardiac sympathetic denervation in Parkinson's disease. J Neurol Sci. 2009;276(1-2):79-83. http://dx.doi.org/10.1016/j.jns.2008.09.005

7. Jain S, Goldstein DS. Cardiovascular dysautonomia in Parkinson disease: from pathophysiology to pathogenesis. Neurobiol Dis. 2012;46(3):572-80. http://dx.doi.org/10.1016/j.nbd.2011.10.025

8. Buob A, Winter H, Kindermann M, Becker G, Möller JC, Oertel WH et al. Parasympathetic but not sympathetic cardiac dysfunction at early stages of Parkinson's disease. Clin Res Cardiol. 2010;99(11):701-6. http://dx.doi.org/10.1007/s00392-010-0170-6

9. Wang X, Thayer JF, Treiber F, Snieder H. Ethnic differences and heritability of heart rate variability in African- and European
American youth. Am J Cardiol. 2005;96(8):1166-72. http://dx.doi. org/10.1016/j.amjcard.2005.06.050

10. Devos D, Kroumova M, Bordet R, Vodougnon H, Guieu JD, Libersa C. Heart rate variability and Parkinson's disease severity. J Neural Transm. 2003;110(9):997-1011. http://dx.doi.org/10.1007/s00702-003-0016-8

11. Task Force of the European Society of Cardiology the North American Society of Pacing Electrophysiology. Heart rate variability: standards of measurement, physiological interpretation, and clinical use. Circulation. 1996;93(5):1043-65. http://dx.doi.org/10.1161/01.cir.93.5.1043

12. Elghozi JL. Variabilité à court terme de la pression artérielle : physiologie et pharmacologie. Ann Pharm Fr. 2008;66(3):158-68. http://dx.doi.org/10.1016/j.pharma.2008.05.002

13. Ranpuria R, Hall M, Chan CT, Unruh M. Heart rate variability (HRV) in kidney failure: measurement and consequences of reduced HRV. Nephrol Dial Transplant. 2008;23(2):444-9. http://dx.doi.org/10.1093/ ndt/gfm634

14. Ponikowski P, Anker SD, Chua TP, Szelemej R, Piepoli M, Adamapoulos $S$ et al. Depressed heart rate variability as an independent predictor of death in chronic congestive heart failure secondary to ischemic or idiopathic dilated cardiomyopathy. Am J Cardiol. 1997;79(12):1645-50. http://dx.doi.org/10.1016/s0002-9149 (97)00215-4

15. May $\mathrm{O}$, Arildsen $\mathrm{H}$. Long-term predictive power of heart rate variability on all-cause mortality in the diabetic population. Acta Diabetol. 2011;48(1):55-9. http://dx.doi.org/10.1007/s00592-010-0222-4

16. Ryan ML, Ogilvie MP, Pereira BM, Gomez-Rodriguez JC, Manning RJ, Vartas PA et al. Heart rate variability is an independent predictor of morbidity and mortality in hemodynamically stable trauma patients. J Trauma. 2011;70(6):1371-80. http://dx.doi.org/10.1097/ TA.0b013e31821858e6

17. Diaz KM, Feairheller DL, Sturgeon KM, Veerabhadrappa P, Williamson ST, Crabbe DL et al. Increased nitric oxide and attenuated diastolic 
blood pressure variability in African Americans with mildly impaired renal function. Int J Hypertens. 2011;2010:137206. http://dx.doi.org/ $10.4061 / 2010 / 137206$

18. Mussalo H, Vanninen E, Ikäheimo R, Laitinen T, Hartikainen J. Short-term blood pressure variability in renovascular hypertension and in severe and mild essential hypertension. Clin Sci (Lond). 2003;105(5):609-14. http://dx.doi.org/10.1042/CS20020268

19. Radaelli A, Perlangeli S, Cerutti MC, Mircoli L, Mori I, Boselli L et al. Altered blood pressure variability in patients with congestive heart failure. J Hypertens. 1999;17(Suppl 12):1905-10.

20. Friedrich C, Rüdiger H, Schmidt C, Herting B, Prieur S, Junghanns S et al. Baroreflex sensitivity and power spectral analysis in different extrapyramidal syndromes. J Neural Transm. 2008;115(11):1527-36. http://dx.doi.org/10.1007/s00702-008-0127-3

21. Baevsky RM, Baranov VM, Funtova II, Diedrich A, Pashenko AV, Chernikova AG et al. Autonomic cardiovascular and respiratory control during prolonged spaceflights aboard the International Space Station. J Appl Physiol. 2007;103(1):156-61. http://dx.doi.org/ 10.1152/japplphysiol.00137.2007

22. Strano S, Lino S, Calcagnini G, Di Virgilio V, Ciardo R, Crutti S et al. Respiratory sinus arrhythmia and cardiovascular neural regulation in athletes. Med Sci Sports Exerc. 1998;30(2):215-9. http://dx.doi.org/ 10.1097/00005768-199802000-00007

23. Pinna GD, Maestri R, La Rovere MT, Gobbi E, Fanfulla F. Effect of paced breathing on ventilatory and cardiovascular variability parameters during short-term investigations of autonomic function. Am J Physiol Heart Circ Physiol. 2006;290(1):H424-33. http://dx.doi.org/ 10.1152/ajpheart.00438.2005

24. Langager AM, Hammerberg BE, Rotella DL, Strauss HM. Very low-frequency blood pressure variability depends on voltage-gated
L-type Ca2+ channels in conscious rats. Am J Physiol Heart Circ Physiol. 2007;292(3):H1321-7. http://dx.doi.org/10.1152/ ajpheart.00874.2006

25. Barbic F, Perego F, Canesi M, Gianni M, Biagiotti S, Constantino G et al. Early abnormalities of vascular and cardiac autonomic control in Parkinson's disease without orthostatic hypotension. Hypertension. 2007;49(1):120-6. http://dx.doi.org/10.1161/01. HYP.0000250939.71343.7c

26. Oka H, Toyoda C, Yogo M, Mochio S. Cardiovascular dysautonomia in de novo Parkinson's disease without orthostatic hypotension. Eur J Neurol. 2011;18(2):286-92. http://dx.doi.org/10.1111/j.14681331.2010.03135.x

27. Hughson RL, Maillet A, Dureau G, Yamamoto Y, Gharib C. Spectral analysis of blood pressure variability in heart transplant patients. Hypertension. 1995;25(4 Pt 1):643-50. http://dx.doi.org/10.1161/01. hyp.25.4.643

28. Rosengård-Bärlund $M$, Bernardi L, Holmqvist J, Debarbieri G, Mäntysaari M, Björkesten C-G et al. Deep breathing improves blunted baroreflex sensitivity even after 30 years of type 1 diabetes. Diabetologia. 2011;54(7):1862-70. http://dx.doi.org/10.1007/s00125$011-2164-y$

29. Estañol B, Delgado G, Bertado N, Callejas C, Medina Z, Infante O et al. Loss of heart rate variability in Parkinson's disease shown by the Poincaré plots during rhytmic breathing. Neurology. 2012;78(Meeting Abstracts 1):P05.196. http://dx.doi.org/10.1212/wnl.78.1_meetingabstracts.p05.196

30. Fluckiger L, Boivin JM, Quilliot D, Jeandel C, Zannad F. Differential effects of aging on heart rate variability and blood pressure variability. J Gerontol A Biol Sci Med Sci. 1999;54(5):B219-24. http://dx.doi.org/10.1093/gerona/54.5.b219 